\title{
Sexual Function in Male Patients with Metabolic Syndrome and Effective Parameters on Erectile Dysfunction
}

\author{
Sacit Nuri Gorgel, Ahmet Gorgel, Ertugrul Sefik \\ Department of Urology, Goksun State Hospital (SNG); Izmir Ataturk Training and Resarch Hospital, En- \\ docrinology and Metabolism Clinic (AG) and Department of Urology, Ardahan State Hospital (ES), Turkey
}

\section{ABSTRACT}

Purpose: We aimed to investigate the relationship between metabolic syndrome and sexual function and effective parameters on erectile dysfunction (ED).

Materials and Methods: A total of 1300 individuals were included in this study between January 2009 and July 2012. All of individuals were asked to fill in an International Index for Erectile Function (IIEF) questionnaire. The presence of metabolic syndrome was determined when any three or more of the five risk factors were present according to the National Cholesterol Education Program (NCEP) Adult Treatment Panel (ATP)-III. Obese individuals were divided into six groups according to modified World Health Organization (WHO) definition. Effective parameters on erectile dysfunction were investigated in individuals with metabolic syndrome.

Results: Metabolic syndrome was detected in 455 individuals (35\%). Mean domain scores of IIEF for all parameters were higher in individuals without metabolic syndrome than individuals with metabolic syndrome $(\mathrm{p}<0.05)$. Mean domain scores of IIEF were lower in individuals with class 3 obesity than individuals with other obese groups ( $p$ $<0.05$ ) for erectile dysfunction. There was statistical difference in terms of mean score of IIEF-Erectile function between smoking and nonsmoking groups ( $<<0.05)$. Seventy percent of individuals with metabolic syndrome and 45\% of individuals without metabolic syndrome had ED ( $p<0.001)$. Logistic regression analysis revealed that waist circumference (WC) was the most important criteria for ED $(\mathrm{p}<0.05)$.

Conclusions: Metabolic syndrome, smoking and obesity seem to be potential risk factors for ED. We recommend individuals with metabolic syndrome, smoking and obesity should be questioned about ED.

\section{ARTICLE INFO}

\section{Key words:}

Obesity; Erectile Dysfunction;

Metabolic Syndrome X; Smoking

Int Braz J Urol. 2014; 40: 56-61

Submitted for publication:

January 22, 2013

Accepted after revision:

October 02, 2013

\section{INTRODUCTION}

Metabolic syndrome is comprised of metabolic risk factors in one individual. This syndrome is also defined as a multidimensional risk factor for cardiovascular disease. It was initially described by a committee of experts from the World Health Organization (WHO) in 1998 (1).

The experts of the National Cholesterol Education Program (NCEP) Adult Treatment Pa- nel (ATP)-III created an operational definition of metabolic syndrome in 2001. In this classification, abdominal obesity, high blood pressure (BP), high fasting blood glucose (FBG), high triglyceride (TG), and low high density lipoprotein (HDL) cholesterol are suggested as risk factors of metabolic syndrome. The existence of any three out of five factors is defined as metabolic syndrome (2).

In economically developed countries, the metabolic syndrome is very common and affects 
up to $30 \%$ of the population, and its incidence continues to increase (3). Endothelial dysfunction occurs frequently in metabolic syndrome and is predictive of future cardiovascular events (4).

It affects the whole arterial system including those that supply blood to the penis (5). Montorsi et al. stated that erectile dysfunction (ED) existed approximately 39 months before cardiac events (6). Briefly, the relationship between metabolic syndrome and cardiovascular disease (CVD) has been established as well as the relationship between CVD and ED (7). However, association between ED and metabolic syndrome has been investigated in few studies (8).

In this study, we aimed to investigate the relationship between metabolic syndrome and sexual function and effective parameters on erectile dysfunction.

\section{MATERIALS AND METHODS}

A total of 1300 consecutive individuals who were admitted to urology and endocrinology clinics were included in the study. Individuals who had history of drug usage, history of surgeries and history of neurologic, psychogenic, cardiovascular diseases were excluded the study.

Individuals filled the IIEF questionnaire by themselves. Erectile Function, Orgasmic Function, Sexual Desire, Intercourse Satisfaction and Overall Satisfaction status were determined using IIEF (9).

All individuals underwent physical examination including measurement of height, weight, hip girth, and waist circumference (WC). Supine WC was measured at the level of umbilicus with the person breathing silently according to the WHO guidelines (10). Blood samples were obtained from all individuals in a fasting state for serum triglyceride (TG), high density lipoprotein (HDL) cholesterol, and fasting blood glucose (FBG) analysis.

The presence of metabolic risk factors were defined as: HDL-cholesterol $<40 \mathrm{mg} / \mathrm{dL}$, Blood Pressure $\geq 130 / 85 \mathrm{mmHg}$; Fasting Glucose $\geq 110 \mathrm{mg} / \mathrm{dL}$; Triglycerides $\geq 150 \mathrm{mg} / \mathrm{dL}$; and Waist circumference $>102 \mathrm{~cm} 2$. The presence of metabolic syndrome was determined according to
NCEP ATP-III guidelines (2). When a patient had three or more risk factors, he was assumed to have metabolic syndrome. Obese individuals were divided into six groups according to modified WHO definition (11).

Effective parameters on erectile dysfunction were investigated in individuals with metabolic syndrome.

\section{Statistical analysis}

Mean age and IIEF domain scores of individuals with and without metabolic syndrome were compared using an independent Student's t-test. $\chi^{2}$-test was applied for association of each risk factor to ED. Statistical significance was defined as $p<0.05$. The statistical analyses were performed with the Statistical Package for the Social Sciences (SPSS.16.0) software program.

\section{RESULTS}

Metabolic syndrome was diagnosed in 455 (35\%) of 1300 individuals and the rest (845 individuals) constituted the group of individuals without metabolic syndrome. The mean age of participating individuals in this study was $57.2 \pm 9.2$ years. Individuals with metabolic syndrome were significantly older than the individuals without metabolic syndrome $(p<0.05)$. Demographics and laboratory findings are shown in Table-1.

Mean domain scores of IIEF for all parameters were higher in individuals without metabolic syndrome than individuals with metabolic syndrome $(p<0.05)$. IIEF-Erectile function domain scores of individuals with and without metabolic syndrome were $15.3 \pm 6.4$ and $20.4 \pm 4.8$, respectively ( $p<0.001$ ). IIEF-Orgasmic function domain scores of individuals with and without metabolic syndrome were $4.3 \pm 3.2$ and $6.4 \pm 4.4$, respectively $(\mathrm{p}<0.05)$. IIEF-Sexual desire domain scores of individuals with and without metabolic syndrome were $3.4 \pm 2.1$ and $5.4 \pm 4.2$, respectively $(\mathrm{p}<0.05)$. IIEF-Intercourse satisfaction domain scores of individuals with and without metabolic syndrome were $8.4 \pm 6.1$ and $11.3 \pm 5.3$, respectively $(\mathrm{p}<0.001)$. IIEF-Overall satisfaction domain scores of individuals with and without metabolic 
Table 1 - Demographics and laboratory findings of the patients.

\begin{tabular}{lcc}
\hline & With metabolic syndrome & Without metabolic syndrome \\
\hline Patient number & 455 & 845 \\
Age (years) & $61.3 \pm 9.3$ & $56.2 \pm 8.2$ \\
WC (cm) & $103.5 \pm 6.3$ & $94.3 \pm 6.8$ \\
FBG & $144.8 \pm 35.3$ & $109.2 \pm 37.4$ \\
TG & $236.3 \pm 113.6$ & $131.4 \pm 56.4$ \\
HDL-cholesterol & $34.7 \pm 8.3$ & $48.5 \pm 10.4$ \\
Hypertension & $232(51 \%)$ & $127(15 \%)$ \\
\hline
\end{tabular}

$\mathbf{F B G}=$ Fasting blood glucose; $\mathbf{H D L}=$ High density lipoprotein; IIEF-EF = International Index for Erectile Function erectile function; $\mathbf{T G}=$ Triglyceride; $\mathbf{W C}=$ Waist circumference.

syndrome were $4.4 \pm 2.2$ and $6.5 \pm 3.2$, respectively $(\mathrm{P}<0.05)$ (Table-2).

Sixty percent of individuals of the smoking group (202 individuals) and 45\% of individuals in nonsmoking group (253 individuals) had ED among individuals with metabolic syndrome. Mean score of IIEF-Erectile function in smoking group was $13.4 \pm 4.3$ and in nonsmoking group was $16.7 \pm 3.3$. There was statistical difference in mean IIEF score between smoking and nonsmoking groups $(\mathrm{p}<0.05)$ (Student's t test).

Obesity was detected in 380 of 455 individuals (83\%) with metabolic syndrome. Mean score of IIEF-Erectile function was $18.4 \pm 5.8$ in class 1 obesity group, $17.6 \pm 3.7$ in class 2 obesity group and $13.4 \pm 4.8$ in class 3 obesity group. Mean score of IIEF-Erectile function was lower in individuals with class 3 obesity than individuals with other obese groups for erectile dysfunction ( $p$ 0.05) (Table-3). Logistic regression analysis revealed that WC was the most important criteria for ED.

\section{DISCUSSION}

Obesity affects at least 400 million adults worldwide (12). In the USA, 40\% of men are expected to be obese by 2020 . ED affects physical and psychosocial health and has a significant impact on the quality of life of sufferers and the partners and families $(13,14)$. ED is one of the most widespread chronic diseases in men (15). Currently, it is widely agreed that atherosclerosis vessels of the penis are the cause of organic ED in the majority

Table 2 - Relationship between the metabolic syndrome and parameters of IIEF questionnaire.

\begin{tabular}{lccc}
\hline IIEF & With metabolic syndrome & Without metabolic syndrome & $P$ \\
\hline Erectile function & $15.3 \pm 6.4$ & $20.4 \pm 4.8$ & \\
Orgasmic function & $4.3 \pm 3.2$ & $6.4 \pm 4.4$ & $<0.05$ \\
Sexual desire & $3.4 \pm 2.1$ & $5.4 \pm 4.2$ & \\
Intercourse satisfaction & $8.4 \pm 6.1$ & $11.3 \pm 5.3$ & \\
Overall satisfaction & $4.4 \pm 2.2$ & $6.5 \pm 3.2$ \\
\hline
\end{tabular}

IIEF-EF = International Index for Erectile Function 
Table 3 - Relationship between the erectile function and obesity groups.

\begin{tabular}{lccc}
\hline Obesity groups & Patients number & Mean score of IIEF-Erectile function & $p$ \\
\hline Class 1 obesity & 164 & $18.4 \pm 5.8$ & $<0.05$ \\
Class 2 obesity & 128 & $17.6 \pm 3.7$ & \\
Class 3 obesity & 88 & $13.4 \pm 4.8$ & \\
\hline Total & 380 & $17.2 \pm 4.6$ & \\
\hline
\end{tabular}

of cases (16). Evidence of this can be seen from the fact that the risk factors for atherosclerosis, such as hypertension, diabetes mellitus (DM), dyslipidemia, sedentary lifestyle, obesity and smoking, are common in men with organic ED $(15,17)$. Moreover, the severity of ED is known to correlate with the number and severity of the above listed disorders, while the combination of these factors raises the risk of developing ED (18). In our study we observed that the mean domain scores of IIEF for all parameters were higher in individuals without metabolic syndrome than individuals with metabolic syndrome.

Among the factors associated with ED are depression, hormonal changes, and vascular or neurologic damage after trauma or surgery. ED is also associated with different endocrine-metabolic disorders like type 2 diabetes mellitus (DM2), and components of metabolic syndrome (MS) such as hypertension, obesity, and dyslipidemia (19).

Metabolic syndrome is a group of risk factors that is responsible for endothelial dysfunction and atherosclerosis (20). Erectile dysfunction is a multifactorial disease. The most common cause of ED is penile vascular insufficiency (21). As shown in previous studies, endothelial dysfunction and ED share common pathophysiologic pathways (22). Cross-sectional studies have documented a concordance between the causes of ED and cardiovascular disease, that is, elements common to the metabolic syndrome $(23,24)$. The relationship between metabolic syndrome and CVD has been established by Wilson et al. (25).

On the other hand, the metabolic syndrome is considered the most important public health threat of the twenty-first century (26). Men with cardiovascular diseases or metabolic syndrome of- ten have erectile dysfunction, probably because of shared factors impairing hemodynamic mechanisms in both the penile and systemic vascular beds (27).

Obesity is a term applied to excess body weight with an abnormally high proportion of body fat. Several studies have indicated that obesity is an independent risk factor for CVD and ED $(28,29)$. Abdominal obesity is associated with increased coagulability, endothelial dysfunction, and inflammation. Increased cytokine levels and other factors which cause insulin resistance and increased cardiovascular risk may be responsible for this condition $(30,31)$.

In our study, the mean score of IIEF-Erectile function was significantly lower in individuals with class 3 obesity than individuals with other obese groups for erectile dysfunction. In addition, we detected that WC was the most important criteria for ED.

Some modifications to the WHO definitions have been made by particular bodies. The surgical literature breaks down "class III" obesity into further categories whose exact values are still disputed (11).

Numerous studies have demonstrated that endothelial dysfunction occurs early in the insulin resistant state and is predictive of future dysfunctional vascular diseases such as ED and CVD (20,32). There is accumulating evidence that waist hip ratio (WHR) and WC are better indicators of the metabolic syndrome and increased risk of CVD $(33,34)$.

In a prospective study of risk factors for $\mathrm{ED}$, the author found that obesity and smoking were positively associated, and physical activity was inversely associated with the risk of developing ED during the 14-year follow-up (35). In our 
study, there was statistical difference in mean IIEF scores between smoking and nonsmoking groups.

In this manuscript the main weakness is that it was carried out on hospitalized individuals, who are not necessarily representative of the general population.

\section{CONCLUSIONS}

Metabolic syndrome is significantly associated with ED. Furthermore, there is a significant association between the increased severity of ED and metabolic syndrome. Abnormal WC is an independent and new metabolic risk factor for ED. Metabolic syndrome, smoking and obesity seem to be potential risk factors for ED. We recommend individuals with metabolic syndrome, smoking and obesity should be questioned about ED.

\section{CONFLICT OF INTEREST}

None declared.

\section{REFERENCES}

1. Alberti KG, Zimmet PZ: Definition, diagnosis and classification of diabetes mellitus and its complications. Part 1: diagnosis and classification of diabetes mellitus provisional report of a WHO consultation. Diabet Med. 1998; 15: 539-53.

2. [No authors listed]: Expert Panel on Detection, Evaluation, and Treatment of High Blood Cholesterol in Adults: Executive Summary of The Third Report of The National Cholesterol Education Program (NCEP) Expert Panel on Detection,Evaluation, And Treatment of High Blood Cholesterol In Adults (Adult Treatment Panel III). JAMA. 2001; 285: 2486-97.

3. Ford ES, Abbasi F, Reaven GM: Prevalence of insulin resistance and the metabolic syndrome with alternative definitions of impaired fasting glucose. Atherosclerosis. 2005; 181: 143-8.

4. Hsueh WA, Lyon CJ, Quiñones MJ: Insulin resistance and the endothelium. Am J Med. 2004; 117: 109-17.

5. Maas R, Schwedhelm E, Albsmeier J, Böger RH: The pathophysiology of erectile dysfunction related to endothelial dysfunction and mediators of vascular function. Vasc Med. 2002; 7: 213-25.

6. Montorsi F, Briganti A, Salonia A, Rigatti P, Margonato A, Macchi $A$, et al.: Erectile dysfunction prevalence, time of onset and association with risk factors in 300 consecutive patients with acute chestpain and angiographically documented coronary artery disease. Eur Urol. 2003 ; 44: 360-4; discussion 364-5.
7. Roumeguère $T$, Wespes $E$, Carpentier $Y$, Hoffmann $P$, Schulman CC: Erectile dysfunction is associated with a high prevalence of hyperlipidemia and coronary heart disease risk. Eur Urol. 2003; 44: 355-9.

8. Bansal TC, Guay AT, Jacobson J, Woods BO, Nesto RW: Incidence of metabolic syndrome and insulin resistance in a population with organic erectile dysfunction. J Sex Med. 2005; 2: 96-103.

9. Rosen RC, Riley A, Wagner G, Osterloh IH, Kirkpatrick $J$, Mishra $A$ : The international index of erectile function (IIEF): a multidimensional scale for assessment of erectile dysfunction. Urology. 1997; 49: 822-30.

10. [No authors listed]: Physical status: the use and interpretation of anthropometry. Report of a WHO Expert Committee. World Health Organ Tech Rep Ser. 1995;854:1-452.

11. Sturm R: Increases in morbid obesity in the USA: 20002005. Public Health. 2007; 121: 492-6.

12. [No authors listed]: Obesity: preventing and managing the global epidemic. Report of a WHO consultation. World Health Organ Tech Rep Ser. 2000; 894: i-xii, 1-253.

13. Ruhm C: Current and future prevalence of obesity and severe obesity in the United States. In NBER Working Paper No 13181; 2007.

14. Hatzimouratidis K, Amar E, Eardley I, Giuliano F, Hatzichristou D, Montorsi F, et al.: Guidelines on male sexual dysfunction: erectile dysfunction and premature ejaculation. Eur Urol. 2010; 57: 804-14.

15. Nicolosi A, Moreira ED Jr, Shirai M, Bin Mohd Tambi MI, Glasser DB: Epidemiology of erectile dysfunction in four countries: cross-national study of the prevalence and correlates of erectiledysfunction. Urology. 2003; 61: 201-6.

16. Melman A, Gingell JC: The epidemiology and pathophysiology of erectile dysfunction. J Urol. 1999; 161: 5-11.

17. Feldman HA, Goldstein I, Hatzichristou DG, Krane RJ, McKinlay JB: Impotence and its medical and psychosocial correlates: results of the Massachusetts Male Aging Study. J Urol. 1994; 151: 54-61.

18. Parazzini $F$, Menchini Fabris $F$, Bortolotti $A$, Calabrò $A$, Chatenoud L, Colli E, et al.: Frequency and determinants of erectile dysfunction in Italy. Eur Urol. 2000; 37: 43-9.

19. Costanzo P, Knoblovits P, Rey Valzacchi G, Gueglio G, Layus 0 : Erectile dysfunction is associated with a high prevalence of obesity and metabolic syndrome. Rev Argent Endocrinol Metab 2008; 45: 142-8.

20. Lakka HM, Laaksonen DE, Lakka TA, Niskanen LK, Kumpusalo E, Tuomilehto J, et al.: The metabolic syndrome and total and cardiovascular disease mortality in middleaged men. JAMA. 2002; 288: 2709-16.

21. Guay AT, Traish A: Testosterone deficiency and risk factors in the metabolic syndrome: implications for erectile dysfunction. Urol Clin North Am. 2011; 38: 175-83. 
22. Sullivan ME, Thompson CS, Dashwood MR, Khan MA Jeremy JY, Morgan RJ, et al.: Nitric oxide and penile erection: is erectile dysfunction another manifestation of vascular disease? Cardiovasc Res. 1999; 43: 658-65.

23. Corona G, Mannucci E, Schulman C, Petrone L, Mansani R, Cilotti A, et al.: Psychobiologic correlates of the metabolic syndrome and associated sexual dysfunction. Eur Urol. 2006; 50: 595-604; discussion 604.

24. Heidler S, Temml C, Broessner C, Mock K, Rauchenwald $\mathrm{M}$, Madersbacher $\mathrm{S}$, et al.: Is the metabolic syndrome an independent risk factor for erectile dysfunction? J Urol. 2007; 177: 651-4.

25. Wilson PW, Kannel WB, Silbershatz H, D’Agostino RB: Clustering of metabolic factors and coronary heart disease. Arch Intern Med. 1999; 159: 1104-9.

26. Traish AM, Guay A, Feeley R, Saad F: The dark side of testosterone deficiency: I. Metabolic syndrome and erectile dysfunction. J Androl. 2009; 30: 10-22.

27. Jackson G: The metabolic syndrome and erectile dysfunction: multiple vascular risk factors and hypogonadism. Eur Urol. 2006; 50: 426-7.

28. Rimm EB, Stampfer MJ, Giovannucci E, Ascherio A, Spiegelman $\mathrm{D}$, Colditz $\mathrm{GA}$, et al.: Body size and fat distribution as predictors of coronary heart disease among middle-aged and older US men. Am J Epidemiol. 1995; 141: 1117-27.

29. Esposito K, Giugliano F, Di Palo C, Giugliano G, Marfella $R$, D'Andrea $F$, et al.: Effect of lifestyle changes on erectile dysfunction in obese men: a randomized controlled trial. JAMA. 2004; 291: 2978-84.
30. McFarlane SI, Banerji M, Sowers JR: Insulin resistance and cardiovascular disease. J Clin Endocrinol Metab. 2001; 86: 713-8.

31. Guerre-Millo M: Adipose tissue hormones. J Endocrinol Invest. 2002; 25: 855-61.

32. Grundy SM: Obesity, metabolic syndrome, and coronary atherosclerosis. Circulation. 2002; 105: 2696-8.

33. Lundgren $H$, Bengtsson C, Blohme G, Lapidus L, Sjöström $\mathrm{L}$ : Adiposity and adipose tissue distribution in relation to incidence of diabetes in women: results from a prospectivepopulation study in Gothenburg, Sweden. Int J Obes. 1989; 13: 413-23.

34. Lean ME, Han TS, Morrison CE: Waist circumference as a measure for indicating need for weight management. BMJ. 1995; 311: 158-61.

35. Bacon CG, Mittleman MA, Kawachi I, Giovannucci E, Glasser DB, Rimm EB: A prospective study of risk factors for erectile dysfunction. J Urol. 2006; 176: 217-21

Correspondence address: Sacit Nuri Gorgel, MD Department of Urology, Goksun State Hospital,

Kahramanmaras, 46600, Turkey Telephone: +90 532 688-2910 E-mail: sngorgel@hotmail.com 